\title{
All patients with giant hiatal hernia require referral to a surgeon, retrospective cohort study
}

\author{
Alexander Ednie ${ }^{1}$, Daniel G. French ${ }^{2}$ \\ ${ }^{1}$ Division of General Surgery, ${ }^{2}$ Division of Thoracic Surgery, Department of Surgery, Dalhousie University, Queen Elizabeth II Hospital—Victoria \\ Campus, Halifax, NS, USA \\ Contributions: (I) Conception and design: Both authors; (II) Administrative support: Both authors; (III) Provision of study materials or patients: \\ Both authors; (IV) Collection and assembly of data: Both authors; (V) Data analysis and interpretation: Both authors; (VI) Manuscript writing: Both \\ authors; (VII) Final approval of manuscript: Both authors. \\ Correspondence to: Daniel G. French, MD, FRCSC. Assistant Professor of Surgery, Division of Thoracic Surgery, Department of Surgery, Dalhousie \\ University, Queen Elizabeth II Hospital—Victoria Campus, 1276 South Park Street, Halifax, NS B3H 2Y9, USA. Email: danielg.french@nshealth.ca.
}

Background: A giant hiatal hernia is defined as having greater than $50 \%$ of the stomach herniated into the chest. Giant hernias have an increased risk of gastric volvulus causing acute gastric obstruction and strangulation. Controversy exists regarding surgical intervention for asymptomatic giant hiatal hernias. The goals of this study are to determine the incidence of giant hiatal hernias found on computed tomography (CT), the number of these patients referred for surgical assessment and/or needing emergent surgical intervention.

Methods: A diagnostic imaging database for the health district was searched from January 2010 to January 2015. Surgical interventions, emergency department encounters, and surgical referrals were reviewed using personal health records.

Results: A total of 357,213 CT reports were searched. Hiatal hernias were identified in 185 patients (50.2\%). Type III and IV hiatal hernias were reported in 75 patients (38\%) including $30(16.2 \%)$ giant hernias. Type IV hernias had the highest percentage of emergency department visits (36.4\%). Seven (23.3\%) patients with a giant hiatal hernia required emergent repair compare to no patient with a non-giant hernia. However, only $6(20 \%)$ patients with a giant hiatal hernia were referred for surgical assessment.

Conclusions: Emergency department encounters and need for emergent surgical intervention were highest among Type III and IV hiatal hernias. Patients with giant hiatal hernia are at increased risk for needing emergent surgery. Patients with a giant hiatal hernia should be referred for surgical assessment because of an increased risk of needing emergent surgical intervention.

Keywords: Hiatal hernia; giant; emergent surgery

Received: 05 January 2020; Accepted: 13 August 2020; Published: 25 November 2020.

doi: $10.21037 /$ ccts-19-47

View this article at: http://dx.doi.org/10.21037/ccts-19-47

\section{Introduction}

Historically all asymptomatic and symptomatic paraesophageal hernias were repaired primarily based on the concern for gastric volvulus and the increased morbidity and mortality associated with an emergent repair. In 2002, Stylopoulos et al. used a Markov Monte Carlo decision analytic model to suggest a watch and wait approach as a safe alternative for asymptomatic paraesophageal hernias, especially in patients over the age of 65 (1). Despite this, the elective repair of asymptomatic paraesophageal hernias remains a controversial topic. There is even more controversy regarding the appropriate management of asymptomatic giant hiatal hernias.

Giant hiatal hernias are those defined as Type III and Type IV paraesophageal hernias where greater than $50 \%$ of the stomach has herniated into the thoracic cavity (2). Mortality with emergent presentation has been reported to be anywhere from $22-40 \%$ compared to $1 \%$ for elective 
Table 1 Outcomes for giant hiatal hernia patients between 2010 2015

\begin{tabular}{lc}
\hline Parameters & Number \\
\hline Median age & $78[70-83]$ \\
Male: female & $1: 4$ \\
Referral to surgeon & $6 / 30(20 \%)$ \\
Patients requiring emergent surgery who & $4 / 7(57.1 \%)$ \\
were electively referred to a surgeon & \\
Documented symptomatic giant hiatal hernia patients \\
Present & $5 / 30(16.7 \%)$ \\
Unknown & $25 / 30(83.3 \%)$ \\
\hline
\end{tabular}

repair $(3,4)$. Furthermore, it has also been shown that emergent repair of giant hiatal hernias is also associated with greater morbidity compared to elective repair (4). Given the significant risk associated with emergent repair of giant hiatal hernias, to the best of our knowledge, there is surprisingly an overall lack of data indicating how many of these patients are being referred to a surgeon for consideration of repair. The objectives for our study are to determine the incidence of giant hiatal hernias in a moderate sized Canadian city, the number of patients with a known giant hiatal hernia being referred for surgical assessment, and incidence of emergent repair in patients with a known giant hiatal hernia. We present the following article in accordance with the Strengthening the Reporting of Observational Studies in Epidemiology (STROBE) reporting checklist (available at https://ccts.amegroups. com/article/view/10.21037/ccts-19-47/rc).

\section{Methods}

This was a retrospective cohort study. After research ethics board approval, the Halifax, Nova Scotia regional health district diagnostic imaging computed tomography (CT) database was searched using the following key terms: hiatal hernia, diaphragmatic hernia, intrathoracic stomach, and paraesophageal hernia over the time period from January 2010 to January 2015, inclusive. All CT scans were individually assessed to classify the type of diaphragmatic hernia as either congenital (Bochdalek and Morgagni) or paraesophageal (sliding and Type II-IV), with giant hiatal hernia defined as greater than $50 \%$ of the stomach in the thoracic cavity. A second reviewer was used if there was any question regarding the classification of hernia based on
CT imaging, and a consensus was reached. Personal health records for each identified case were further analyzed to record: emergency department visits, clinic notes representing referrals to thoracic or general surgery for hernia repair, and operative notes for elective or emergent hernia repair. Additionally, we analyzed emergency department charts to determine if patients were presenting with symptoms related to their hiatal hernia. Duplicate CT scans demonstrating a hiatal hernia in the same patient were excluded.

Categorical variables were analyzed for statistical significance using Fisher's exact test. Numerical variables were compared using the student's $t$-test or the Wilcoxon rank sum wherever appropriate. A P value less than 0.05 was considered significant and all tests of significance were two-sided. Numerical continuous data was expressed as median value with interquartile range $\left(25^{\text {th }}-75^{\text {th }}\right.$ percentile $)$. Statistical calculations were performed using SPSS 22 (IBM, Armonk, NY, USA).

The study was conducted in accordance with the Declaration of Helsinki (as revised in 2013). The study was approved by research ethics board of IWK Research Ethics Board (ROMEO) (No. 4276) and individual consent for this retrospective analysis was waived.

\section{Results}

Between January 2010 and January 2015 a total of 357,213 CT chest and CT abdomen reports were searched for the key terms identifying 406 patients with a diaphragmatic hernia. Table 1 summarizes the patient demographic and classification of hernias. The median age of all patients with a diaphragmatic hernia was 78 [70-83] with a gender predominance favoring female $(4: 1)$.

Congenital diaphragmatic hernias were identified in 221 patients (54.4\%), while hiatal hernias (sliding and Type IIIV) were identified in 185 patients $(45.5 \%)$. Of the hiatal hernias, 75 patients $(40 \%)$ had either Type III or IV. Thirty patients (40\%) of these had giant hiatal hernias (Figure 1).

Patients with Type III hernias had the most hernia related emergency room (ER) visits, while 5 patients (16.6\%) with giant hiatal hernias had presented to the ER with hernia related symptoms (Figure 2). Only $20 \%$ of patients with a giant hiatal hernia were referred for surgical opinion. Seven patients $(23.3 \%)$ with a documented giant hiatal hernia required emergent surgical repair. No patients with Type I-II hernias required emergent repair. Only 4 (57\%) of those patients with a giant hiatal hernia who required emergent surgery were referred for elective surgical repair 


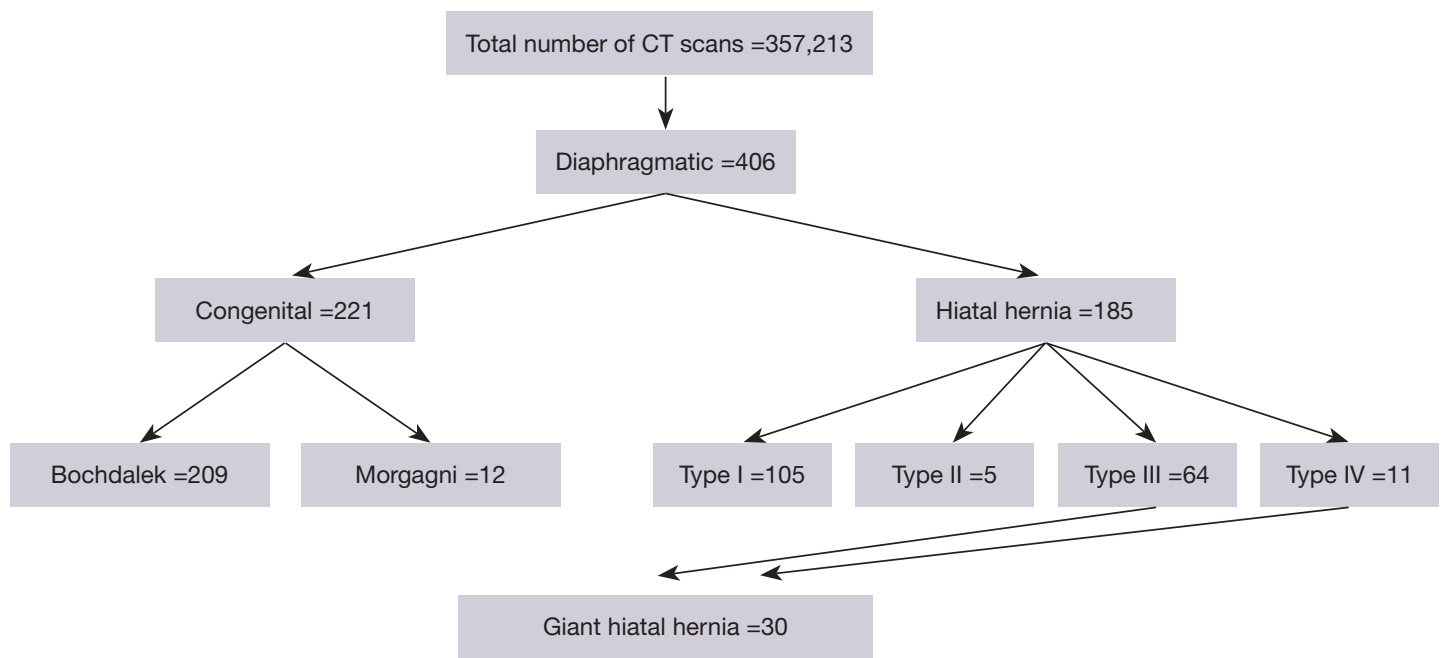

Figure 1 Breakdown of diaphragmatic hernias identified by CT from 2010 to 2015. CT, computed tomography.

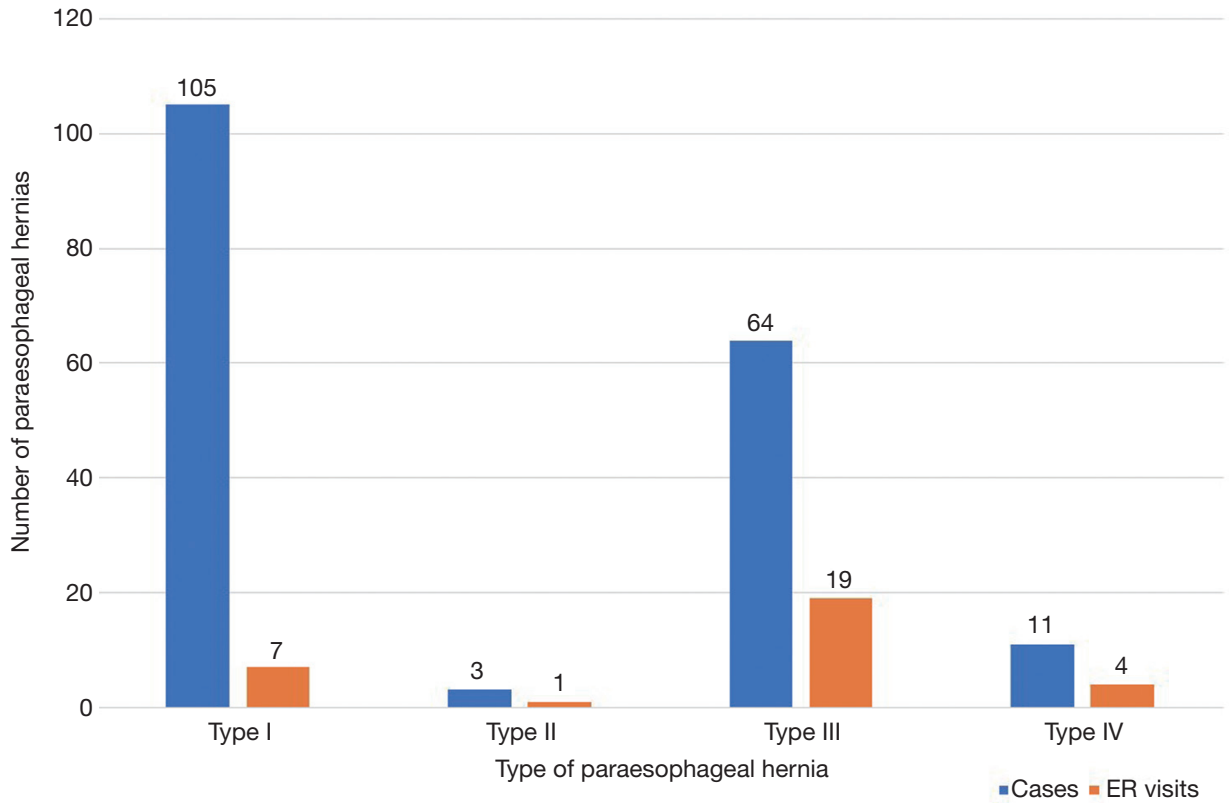

Figure 2 Number of paraesophageal hernias based on CT and those cases presenting to ER with hernia related symptoms between 20102015. CT, computed tomography; ER, emergency room.

(Table 1). No patients died as a result of their hiatal hernia or repair over our period of analysis.

\section{Discussion}

In summary, this retrospective cohort study found that the majority of diaphragmatic hernias are congenital. In our population, we found that $16 \%$ of all hiatal hernias were giant. We also identified that the majority, $80 \%$, of patients with giant hiatal hernias were not being referred to a surgeon for possible repair. Only $57 \%$ of patients with a giant hiatal hernia, who required emergency surgery, had been referred to a surgeon for possible elective management. The majority of patients presenting to the emergency department with symptoms related to their hiatal hernia were Type III and IV. 
The management of asymptomatic hiatal hernias still remains a controversial subject. Stylopoulos et al. demonstrated that above the age of 65 the risk of elective repair of asymptomatic hernias outweighed the annual risk of major complications (1). Carrott et al. have suggested that symptoms associated with paraesophageal hernias are more extensive than previously thought, and that truly asymptomatic patients are in fact rare (5). Both Low et al. and Carrott et al. have also demonstrated that repair of paraesophageal hernias can lead to both subjective and objective improvements in respiratory function, a symptom not typically associated with paraesophageal hernias $(6,7)$. Additional studies have also demonstrated a resolution of anemia, as well as improved exercise tolerance from decreasing compression of the left atrium as a result of elective paraesophageal hernia repair $(8,9)$. Furthermore, Carrott et al. also found that patients had an overall improvement in symptoms not typically associated with hiatal hernia, that being: early satiety, chest pain, shortness of breath, and cough, in addition to those classic symptoms described in the literature: acid reflux and dysphagia (5). This was primarily the result of an appropriate history taken by the surgeon during the patient encounter, where a complete evaluation of typical and atypical symptoms, as well as their evolution over time were assessed. Together these studies would suggest that patients with large paraesophageal hernias may have symptoms that are not fully evaluated, and are therefore possibly not being appropriately referred for a surgical assessment.

We found that in our region of Canada, greater than $40 \%$ of patients with known giant hiatal hernias who required emergency surgery had not previously been referred to a surgeon. It is not expected that all patients referred will be candidates for surgical resection. However, a discussion between the surgeon and patient should take place to determine if the patient is truly asymptomatic and to discuss the surgery risks and benefits of repair in a typically older demographic with comorbidities. Despite these reported benefits of surgical repair, this study suggests a lack of surgical referral in those patients who could potentially derive benefit from paraesophageal hernia repair (6-9). Hesitation to refer may be due in part to primary care physician reluctance based on advanced age and concern of intraoperative and perioperative morbidity and mortality.

Our results show the median age of patients with a giant hiatal hernia is 78 years old. Intraoperative and perioperative morbidity and mortality are common concerns when assessing surgical risk in elderly patients. However, Parker et al. found no statistical difference in overall morbidity or mortality associated with laparoscopic paraesophageal hernia repair comparing patients less than 69 years old to patients greater than 80 years old, concluding that safe laparoscopic surgical repair can be accomplished in the elderly (10). Furthermore, since Stylopoulos et al. study in 2002, a study by Kaplan et al. in 2015 found lower rates of morbidity and mortality associated with elective repair of hiatal hernias and suggested that frailty was the main factor effecting surgical outcome (11). Assessment of operative risk, surgical approach, and risk of requiring emergent operative intervention is best determined by a surgeon familiar with preforming hiatal hernia repairs and the postoperative management.

In our study, we found that patients with giant hiatal hernias were more likely to present to the emergency department with symptoms and ultimately require emergent repair. While we did not specifically look at length of hospital stay, or morbidity, several other studies have found higher mortality rates and length of hospital stay associated with emergent repair $(2,3)$. The higher risk of emergent repair and the associated increased risk of mortality for patients with a giant hiatal hernia, further supports the need to refer these patients for surgical assessment to determine operability.

This study is limited by several issues. This is a retrospective study, and therefore the conclusions are limited to the original data collection in our electronic health record. Secondly, our patient population is limited to the key terms listed used to search our diagnostic imaging database, and as such limited to the radiologist's reports. Therefore, we could potentially be missing cases in our population if the finding is not dictated in the radiology report. This may be only a small limitation regarding our giant hiatal hernia outcomes, given that most radiologist, when asked at our local institution, say they would comment on hiatal hernias even if chronic. Thirdly, assessment of symptoms from ER notes were limited. There were several patient encounters where the reason for visit was chest pain with a negative cardiac workup, but a known giant hiatal hernia which could potentially be attributed to their chest pain.

In conclusion, congenital and Type I paraesophageal hernias compromise the majority of diaphragmatic hernias. Emergency department encounters and need for emergent surgical intervention were highest among Type III and IV hiatal hernias. Additionally, patients with giant hiatal hernias are at increased risk for needing emergent surgery. Patients with Type III and IV hernias, and especially those with a giant hiatal hernia, should be referred for surgical 
assessment because of an increased risk of needing emergent surgical intervention and the previously documented increased morbidity and mortality emergent surgery entails.

We could not identify any study assessing referral patterns for paraesophageal hernias, and therefore cannot compare to other populations to suggest whether this is truly a local phenomenon and could potentially be an area of further investigation. Additionally, surgical decision-making tools to help patients and practitioners determine appropriate surgical candidates, weighing intra and perioperative risk versus symptoms could potentially be developed.

\section{Acknowledgments}

This study was presented internationally at the Society of Thoracic Surgeons (STS) conference in 2018, as well as at the Canadian Association of Thoracic Surgeons (CATS) annual meeting in 2018 in the form of poster presentations. Funding: None.

\section{Footnote}

Reporting Checklist: The authors have completed the STROBE reporting checklist. Available at https://ccts. amegroups.com/article/view/10.21037/ccts-19-47/rc

Data Sharing Statement: Available at https://ccts.amegroups. com/article/view/10.21037/ccts-19-47/dss

Conflicts of Interest: Both authors have completed the ICMJE uniform disclosure form (available at https://ccts. amegroups.com/article/view/10.21037/ccts-19-47/coif). The authors have no conflicts of interest to declare.

Ethical Statement: The authors are accountable for all aspects of the work in ensuring that questions related to the accuracy or integrity of any part of the work are appropriately investigated and resolved. The study was conducted in accordance with the Declaration of Helsinki (as revised in 2013). The study was approved by research ethics board of IWK Research Ethics Board (ROMEO) (No. 4276) and individual consent for this retrospective analysis was waived.

Open Access Statement: This is an Open Access article distributed in accordance with the Creative Commons Attribution-NonCommercial-NoDerivs 4.0 International License (CC BY-NC-ND 4.0), which permits the noncommercial replication and distribution of the article with the strict proviso that no changes or edits are made and the original work is properly cited (including links to both the formal publication through the relevant DOI and the license). See: https://creativecommons.org/licenses/by-nc-nd/4.0/.

\section{References}

1. Stylopoulos N, Gazelle GS, Rattner DW. Paraesophageal hernias: operation or observation? Ann Surg 2002;236:492500; discussion 500-1.

2. Kahrilas PJ, Kim HC, Pandolfino JE. Approaches to the diagnosis and grading of hiatal hernia. Best Pract Res Clin Gastroenterol 2008;22:601-16.

3. Skinner DB, Belsey RH. Surgical management of esophageal reflux and hiatus hernia. Long-term results with 1,030 patients. J Thorac Cardiovasc Surg 1967;53:33-54.

4. Polomsky M, Jones CE, Sepesi B, et al. Should elective repair of intrathoracic stomach be encouraged? J Gastrointest Surg 2010;14:203-10.

5. Carrott PW, Hong J, Kuppusamy M, et al. Clinical ramifications of giant paraesophageal hernias are underappreciated: making the case for routine surgical repair. Ann Thorac Surg 2012;94:421-6; discussion 426-8.

6. Low DE, Simchuk EJ. Effect of paraesophageal hernia repair on pulmonary function. Ann Thorac Surg 2002;74:333-7; discussion 337.

7. Carrott PW, Hong J, Kuppusamy M, et al. Repair of giant paraesophageal hernias routinely produces improvement in respiratory function. J Thorac Cardiovasc Surg 2012;143:398-404.

8. Haurani C, Carlin AM, Hammoud ZT, et al. Prevalence and resolution of anemia with paraesophageal hernia repair. J Gastrointest Surg 2012;16:1817-20.

9. Naoum C, Falk GL, Ng AC, et al. Left atrial compression and the mechanism of exercise impairment in patients with a large hiatal hernia. J Am Coll Cardiol 2011;58:1624-34.

10. Parker DM, Rambhajan AA, Horsley RD, et al. Laparoscopic paraesophageal hernia repair is safe in elderly patients. Surg Endosc 2017;31:1186-91.

11. Kaplan JA, Schecter S, Lin MY, et al. Morbidity and mortality associated with elective or emergency paraesophageal hernia repair. JAMA Surg 2015;150:1094-6.

doi: $10.21037 /$ ccts-19-47

Cite this article as: Ednie A, French DG. All patients with giant hiatal hernia require referral to a surgeon, retrospective cohort study. Curr Chall Thorac Surg 2020;2:35. 